\title{
Strategic Foresight Techniques for Consumer Protection: Prepare for the Future
}

\author{
Rajat Sharma
}

\begin{abstract}
The genesis of this article lies in the current thought processes across the world about the need for developing insights into the emerging consumer protection scenario and needs, in the context of likely future products and services. Governments are keen to having a clear sense of the kind of regulatory issues, and protection mechanisms needed in the markets of the future, to enable a proactive response in setting in place effective consumer protection mechanisms. The purpose of the article is to facilitate better understanding of the momentous changes all around arising from disruptive technologies and innovations, resulting in the need to re-invent governance and systems to face the future challenges and capitalize on opportunity galore.
\end{abstract}

Index Terms-Foresight, Consumer Protection, Privacy, Technology.

\section{INTRODUCTION}

The world has continuously witnessed disruptive changes in the past that have resulted in technological, cultural as well as social shifts in the conduct of its citizens. The change so far was gradual and organizational systems that survived, were able to adopt and adapt to these challenges. However, what we have witnessed till now and what we assume was easy to apprehend, may not be true any longer. There is a need to understand and sensitize that the world is going to change momentously in near future and the pace and scale of change is unprecedented. The current systems of governance and consumer protection mechanisms are clearly inadequate and in the absence of suitable mechanisms, there is an urgent need of new tools and techniques to capitalize on the opportunities attached.

As we enter 2017, many industries and enterprises are witnessing an influx of new technologies and scientific breakthroughs. Cloud Computing, 3D Printing, Virtual Reality, Artificial Intelligence, Internet of things are now no longer the buzz words. Many believe that the technology shifts in these domains has already happened with the advent of their multiple versions such Internet 1.0 and 2.0. However, we are just at the cusp of the shift and the technological advancements are going to fundamentally change the business ways of current organizations. Taking example of Cloud Computing, many organizations are yet to comprehend the complete value by embracing the developments in this technology. No doubt many companies such as Amazon, Microsoft, Adobe, etc. have gained enormously by adopting Cloud Computing, many others are

Rajat Sharma, Ph.D., Assistant Professor, Indian Institute of Management Kashipur, India. struggling to gel it with their overall business goals. The two initial phases of Cloud, namely the SaaS and the Big Data have already generated huge value for the businesses and now Big Compute is all set to be the next big opportunity for them. Big Compute is a high performance computing that enable users and algorithms to shift from backward looking analysis (Big Data) to forward looking analytics to drive predictive insights and predictions. For instance, Big Compute enabled Deep Learning, adopted by Google, will enable new competences and fuel further innovation in driverless driving, robotics, medical imaging etc. Such technologies, besides delivering enormous benefits, may also results in frauds and abuse of technology. At the receiving end of the technology are the consumers who are subjected to content breach of their privacy and erosion of product ownership. Policymakers will have to be prepared for such technological threats.

No doubt these technological capacities have the capability to benefit consumers in many ways, however the way the technology is helping companies collect vast amount of customer data, without them understanding the implications, raises the need to best protect customers in such cases. Products and their functions are likely to become very complicated that consumers will find it very difficult to understand and react. Information asymmetry, no proper training, push notifications, etc., are already creating consumer protection issues. These will require a different approach to protection, such as an application of Strategic Foresight techniques to invent the future.

\section{STRATEGIC ForESIGHT: AN UNDERSTANDING}

Preparing for future is no easy task. It needs firstly developing a mindset and then the necessary resources that can help in transcending the constraints. There is a possibility of predicting the future by focusing on the present trends and simulating them to future, i.e., by using the technique called Forecasting. There is also a methodology to prepare for the future and shape it accordingly by thoroughly looking at the clues and indicators of evolving developments in technology, science and society. Ben Martin (1995) defines it as "the process involved in systematically attempting to look into the longer-term future of science, technology, the economy and society with the aim of identifying the areas of strategic research and the emerging of generic technologies likely to yield the greatest economic and social benefits". The essential difference between current techniques of forecasting and foresight is that the former extrapolates the trends as they are emerging which of necessity do not take the disruptive 
technologies and innovations in account which can often make these projections meaningless. E.g. the advent of e-commerce. Foresight on the other hand allows you to build alternate scenarios of the future and to work at innovative strategies through back casting techniques leading to desired outcomes, which are not possible through forecasting. Foresight uses the latest technology like Cloud Computing, Big Data Analytics, Internet of Things, Artificial Intelligence etc., in conjunction with more instinctive assessments and insights by people to foresee domain-specific future scenarios.

A robust exercise of this nature would call for tools and techniques, embedded in the latest sciences in this arena. Foresight is the primary modern tool shaping the thinking in this context. "Those who make magic, see the future before others" says Travis Kalanick (CEO, Uber). 2In the VUCA world we live in, with technological explosion and disruptive innovation all around, being able to see and influence the shape of things to come is proving to be increasingly essential, both for survival and success. In understanding and application of this powerful tool named Foresight may lie solutions of many governance problems including possible consumer protection issues in the future.

\section{WAY FORWARD}

The way forward is to create a detailed list of consumer protection issues, and then move on to explicating the key aspects of strategic foresight to create future settings. After we build the possible future scenarios, it would be possible to design and put in place appropriate legal and policy frameworks, regulatory structures and enforcement/ advocacy modalities for protecting the consumers from present and emerging threats like digital privacy, cyber frauds, etc.

\section{REFERENCES}

[1] Cuhls, K. (2003). From forecasting to foresight processes-new participative foresight activities in Germany. Journal of forecasting, 22(2-3), 93-111.

https://doi.org/10.1002/for.848

[2] economictimes.indiatimes.com/small-biz/startups/those-who-make-magi c-see-the-future-before-anybody-else-uber-ceo-travis-kalanick/articlesho w/50608857.cms 